\title{
LA PRIMACÍA ENTRE ARTE, RELIGIÓN Y FILOSOFÍA. Un debate abierto desde el Romanticismo
}

\author{
Raquel Cascales Tornel \\ Universidad de Navarra
}

\begin{abstract}
Resumen: El Romanticismo miró la Ilustración como una época que, al apostar por la racionalidad de manera casi exclusiva, rompió la unidad entre distintos ámbitos del saber. La conciencia de esa falta de unidad impulsa la reflexión de muchos intelectuales sobre cómo volver a alcanzarla, tarea que al principio los románticos hacen recaer en el arte. En concreto, el grupo de los Nazarenos, muy ligado al Athenäum, apostó por recuperar esta unidad, que pronto adquirió tintes políticos, mediante la "religión del arte". También otros autores idealistas, como Schelling, consideraron que el arte debía ocupar el lugar primordial en el sistema filosófico. Frente a ellos destaca la figura de Hegel, que rechazará cada vez con más fuerza la mistificación romántica del arte. Aunque, como se verá, en un inicio Hegel también habla de la "religión del arte", en su obra de madurez distingue entre arte, religión y filosofía, dejando claro el lugar primordial que ocupa la racionalidad filosófica en su sistema. Revisando estas cuestiones desde la perspectiva más contemporánea, Inciarte considera que, a pesar de la rotundidad del pensamiento hegeliano, estas tensiones no pueden quedar resueltas desde un enfoque meramente reflexivo, sino que sólo encuentran una salida cuando se tratan en el nivel práctico de la vida.
\end{abstract}

Palabras clave: Arte, Religión, Filosofía, Romanticismo, Hegel, Inciarte.

The Primacy between Art, Religion and Philosophy. An open Debate since Romanticism 
Raquel Cascales

Abstract: Romanticism looked at the Enlightenment as a time that, by betting on rationality almost exclusively, broke the unity between different fields of knowledge. The awareness of this lack of unity impels the reflection of many intellectuals on how to regain it, a task that at first the romantics made fall into in art. In particular, the group of The Nazarenes, closely linked to the Athenäum, opted to recover this unity, which soon acquired political connotations, through the "religion of art." Other idealist authors, like Schelling, also considered that art should occupy the primary place in the philosophical system. Before them stands the figure of Hegel, who will increasingly reject the romantic mystification of art. Although, as we shall see, at first Hegel also speaks of the "religion of art", in his later works he distinguishes between art, religion and philosophy, making clear that in his system the primary place is occupied by the philosophical rationality. Looking at these issues from a more contemporary perspective, Inciarte considers that despite the rotundity of Hegelian thought, these tensions cannot be solved from a purely reflective approach, but only find a way out when they are dealt with at the practical level of life.

Keywords: Art, Religion, Philosophy, Romanticism, Hegel, Inciarte.

Recibido: 30/3/2017 Aceptado: 10/6/2017

En este volumen de homenaje a Cultura y verdad de Fernando Inciarte quiero abordar uno de los temas que más le interesaban: la tensión aparentemente irreconciliable entre arte y religión, por un lado, y religión y filosofía por otro. Estas cuestiones se las plantea recogiendo la interesante discusión que sobre ellas se dio a partir del romanticismo, una época histórica que el autor conocía muy bien. En ese momento se sienten dichas relaciones con especial crudeza y se tratan de resolver. En este artículo revisaré en primer lugar cómo los autores románticos consideran el arte como la esfera de diso- 
La primacia entre arte, religión y filosofía

lución de estas tensiones. Para ello expondré cómo algunos de ellos, entre los que se encuentra el grupo de los Nazarenos, trataron de unificar arte y religión en la "religión del arte" con el fin de que supusiera un impulso político para la Alemania de ese momento. En segundo lugar, mostraré dos respuestas a la tensión aquí planteada: la de Hegel, que cerrará esta discusión al resolverla a favor de la racionalidad de la filosofía, y la de Inciarte, que defenderá que estas tensiones sólo pueden resolverse en la vida.

\section{La exaltación romántica del arte}

Las reflexiones estéticas y el arte fueron catalizadores de las inquietudes de la mayoría de los intelectuales románticos, un punto de confluencia en el que muchos creyeron encontrar la solución a la separación de las diferentes esferas de la vida que la Ilustración había provocado. Tras el periodo ilustrado, en el que se dio todo el peso a la razón, el romanticismo rescató la fuerza unificadora de los mitos y puso cada vez más interés en el arte. Por esta razón, Grecia se convirtió entonces en símbolo de una sociedad en la que podían convivir arte, política y religión. La conciencia de esa falta de unidad impulsará la reflexión de muchos intelectuales sobre cómo poder volver a alcanzarla, tarea que al principio parecerá recaer en el arte, pero cada vez más dejará paso a la filosofía.

El romanticismo se desarrolló en diferentes núcleos literarios — como el Sturm und Drang - y filosóficos. El núcleo principal del romanticismo filosófico es el movimiento congregado en torno a los hermanos Schlegel y su 
revista Athenäum (1798-1800)ํㅜㄹ llamado también el Círculo de Jena o los Frübromantik de Jena. De hecho, fue Friedrich Schlegel el que acuñó el sustantivo "romanticismo", que en un principió se usó para aludir a un tipo de literatura de comienzos del siglo XIX que miraba hacia lo medieval. Con el tiempo, sin embargo, la literatura romántica se desarrolló, fue adquiriendo diferentes matices y este concepto se amplió.

Frente al espíritu ilustrado, los románticos consideraron la idea de belleza como el eslabón perdido "entre las leyes de la naturaleza, instituidas por el entendimiento, y el uso múltiple e indefinido que la razón hace de esa diversidad de leyes particulares" (Sánchez Meca, 2013: 146). Para ellos, el acto estético sería el culmen de la razón, en el que la necesidad del entendimiento y la libertad de la imaginación se integran con vistas a un fin. Lo que los románticos descubren es que el sentido estético no implica una relación determinante con los objetos, y por tanto la obra de arte se convierte en un símbolo en el que la libertad se realiza o, al menos, en el que "podemos intuir cómo podría ser el mundo si la libertad se realizara" (Sánchez Meca, 2013: 146).

A esta mirada sobre el arte se une en la época romántica el desarrollo de lo que Innerarity denomina una mitología de la razón que, frente el mecanicismo científico ilustrado, trata de sintetizar todas las potencialidades de la razón. Además, también se desea revalorizar tanto el papel de la imaginación

${ }^{1}$ Para profundizar en el papel de esta revista y su relación con el círculo romántico de Novalis, Fichte o Schleiermacher ver Martínez, 1992. 
y de la sensibilidad como el poder cohesionador que siempre han tenido los mitos para el ordenamiento político y social (Innerarity, 1993: 47).

Esta remitologización de la belleza forma parte de una vuelta al mito en distintos ámbitos de la cultura impulsada por el movimiento artístico Sturm und Drang y especialmente por Johann G. Herder. Este conocido autor escribe en 1767 "De la nueva utilización de la mitología”, un artículo en el que reflexiona sobre la estructura poética de los mitos y su papel para interpretar la historia, y en el que propone la necesidad de crear una mitología política adecuada a la situación histórica en la que se encuentra. Dicha situación es precisamente la Revolución Francesa, un vuelco político que, tras un entusiasmo inicial, Alemania termina rechazando cuando se ve amenazada por Napoleón. Para ese momento, la resistencia a lo francés no es ya sólo una cuestión política sino plenamente espiritual, puesto que, en el giro que está dando en sus planteamientos, Francia se está convirtiendo en representante de un laicismo que los alemanes consideran que está corroyendo Europa. De ahí que se sientan con una mayor necesidad de contraatacar intelectual y artísticamente.

\subsection{La unificación del arte}

En este contexto, el arte comienza a configurarse como el ámbito adecuado para recuperar la libertad, lo infinito y lo divino, además de traer a la conciencia un pasado marcado por la armonía y la unidad social. Los románticos son conscientes de la influencia que tienen la estética y el arte en el espíritu individual y en el espíritu de los pueblos. Friedrich Schiller, por ejemplo, en Cartas para la educación estética del hombre (1794), considera que 
el arte eleva las divisiones internas que plantea el mundo moderno y reunifica nuestra naturaleza sensorial y espiritual, de modo que las acciones morales y políticas ya no vienen impuestas externamente sino que están integradas de tal modo en la persona que es libre al realizarlas ${ }^{2}$.

Al mismo tiempo, en Sobre la poesía ingenua y sentimental, tratará el tema de la unidad perdida al contraponer la poesía antigua con la moderna. Considera que la ingenuidad de la poesía antigua significa que en aquellos tiempos el sujeto no se sentía contrapuesto a la naturaleza, sino que vivía en unidad armónica con el mundo ${ }^{3}$. Era precisamente esa armonía la que hacía innecesaria la mediación de la reflexión. Sin embargo, el sujeto de la época moderna ha perdido ese mundo y esa armonía, y la distancia que siente entre su sensibilidad y su inteligencia no le permite encontrar soluciones. La conciencia de la escisión con el mundo, con la naturaleza, lleva consigo un aumento de la reflexividad que se transmite a la poesía que realiza. Es a través de la reflexión como el poeta reconstruirá dicha armonía. Por tanto,

${ }^{2}$ De ahí que pueda hablarse de un progresivo proceso de estetización de la política (Marchán Fiz, 2010: 280-289). A esta estetización de la política, que sigue la idea romántica del arte y se continuará en l'art pour l'art, se le contrapondrá, como afirma Benjamin, la politización del arte: "Así sucede con la estetización de la política que propugna el fascismo. Y el comunismo le responde por medio de la politización del arte" (Benjamin, 2008: 47).

${ }^{3} \mathrm{El}$ poeta ingenuo es un poeta que lleva la naturaleza dentro de sí mismo, que la vive, que la siente. Tan compenetrado está con ella que se podría decir que el poeta ingenuo no siente la naturaleza, sino que siente naturalmente. El sentimental, en cambio, no posee la naturaleza; para él la naturaleza es, según un concepto netamente kantiano, un ideal. La naturaleza en él no está más que en el pensamiento, pero no encarnada en su vida. 
La primacia entre arte, religión y filosofía

para Schiller, aunque la quiebra del mundo moderno incremente la nostalgia, también estimula la reflexión y enriquece el arte. Dicha reflexividad, que va a marcar todo el arte hasta nuestros días, comporta el traslado del foco de lo bello a lo "interesante". Schiller trató de alcanzar un tercer estadio que superara las dos épocas: esta síntesis hubiera debido ser la plenitud del romantiromanticismo.

En esta contraposición entre sujeto y naturaleza lo que está en juego no son dos épocas, sino dos maneras o modos de sentir. Schiller estaría "elevando el estadio histórico a la categoría de un estado estético" (Marchán Fiz, 2010: 214). En efecto, lo que aquí late no es sólo la Querelle des anciens et des modernes o, como se presenta en este momento, entre los clásicos y los románticos, sino el peso de la conciencia histórica que se va a desarrollar a lo largo del romanticismo. Esta mirada al pasado, a lo clásico, a lo mitológico, no sólo es un rechazo de la Ilustración sino que se convierte en el sello de identidad del movimiento romántico.

De hecho, implica una cierta continuidad desde la Ilustración, pues ya desde que Winckelmann exaltara el mundo antiguo contraponiéndolo con el moderno se había considerado la escultura griega como el modelo supremo del arte, no sólo por su perfección estética sino por simbolizar una civilización cohesionada. La cohesión proviene de que no había separación entre arte, religión y política y, por tanto, tampoco había una separación nítida entre arte, culto y cultura (Inciarte, 2004). La diferencia que sí hay que señalar respecto a la Ilustración es que Grecia ya no es en el romanticismo sólo un modelo perfecto del pasado, sino que se toma como proyecto (Assunto, 1990). En este sentido, Alemania desea ser la nueva Grecia. 
Raquel Cascales

\subsection{La "religión del arte"}

La profundización en la historia y la mitología antigua configuran de forma determinada el espíritu romántico: frente a los antiguos, ellos son los modernos; frente a la racionalidad, ellos son el sentimiento, frente a Oriente, ellos son Occidente; frente a los paganos, ellos son cristianos ${ }^{4}$. Esta misma mirada hacia la historia pasada hace que algunos autores tiendan también a idealizar la época medieval como aquella en la que el esplendor de la religión vibraba en todos los ámbitos de la sociedad. Dicha idealización va de la mano de la estrecha relación entre arte y religión, que llevará a concebir el arte como una nueva religión capaz de aunar los espíritus tanto individual como socialmente.

\footnotetext{
${ }^{4}$ Safranski pone de manifiesto que las investigaciones sobre Oriente (India, China y Egipto) hacen que se desmorone la confianza que Occidente tenía en sus orígenes, ya que esas culturas más antiguas se descubren como la verdadera cuna de la sabiduría espiritual: "La comprensión que Occidente tenía de sí mismo se viene abajo. Junto con Zoega, Kanne, Welcker, quienes conducen a esta lejanía espacial y espiritual, son especialmente Joseph Görres, Friedrich Schlegel y Georg Friedrich Creuzer. Görres publicó en 1810 la Historia de los mitos del mundo asiático. En ese mismo año comienza la publicación de la monumental obra de Creuzer titulada Simbolismo y mitología de los pueblos antiguos, especialmente de los griegos. Friedrich Schlegel ya en su Discurso sobre mitología del año 1799 había dicho: «En Oriente hemos de buscar lo supremo romántico», estudia sánscrito en París, y en 1808 publica el tomo Sobre la lengua y la sabiduría de los indios" (Safranski, 2009: 141-142). Este interés por el mundo oriental (que volverá a ponerse en auge en los movimientos contraculturales del siglo XX), provocó por reacción un afán por subrayar lo propio, especialmente en lo que a la religión cristiana se refiere.
} 
Ahora bien, ¿¿qué es la "religión del arte” y cómo se forjó? En primer lugar, se fue difundiendo la idea de que el arte y la religión se asientan sobre el sentimiento, especialmente a través de obras como Efusiones del corazón de un hermano lego amante del arte, de Wackenroder (1796-97) o Fantasias sobre el arte, de Tieck (1799). Para estos autores, el sentimiento es lo que nos permite una verdadera vinculación con Dios, presente en su creación. De ahí la importancia del lenguaje del arte, ya que "el arte es la prolongación creativa de la Naturaleza armónica por medio de los hombres" (Jamme, 1998: 17). En este sentido, se empieza a vincular cada vez más el arte con lo religioso, al tiempo que adquiere progresivamente un sentido redentor o salvador que estará presente en gran parte de esta generación de autores. El arte vendría a cubrir así en la sociedad moderna la función modeladora que la religión habría tenido en otras épocas (Domínguez, 2003: 124). De hecho, durante esta época el arte llegará a concebirse como una dimensión superior a la religión, como se verá a continuación.

Otro factor muy importante fue la recuperación de la vieja pintura alemana tardomedieval así como de la pintura holandesa de los siglos anteriores. Se desarrolla un creciente interés por un arte que había quedado sumido en el olvido y el desprestigio a causa de la concepción iconoclasta del protestantismo ${ }^{5}$. Esta revitalización artística tuvo una gran repercusión en los pintores

${ }^{5}$ Comentan Honour y Fleming que Lutero no provocó la iconoclasia, su actitud hacia la pintura y la escultura fue más indiferente que hostil. Sin embargo sí hubo protestantes más extremistas que consideraban las imágenes pecaminosas e idolátricas, especialmente Calvino, que dominó el mundo protestante a partir de mediados del siglo XVI (2002: 471). 
alemanes porque que les llevó a descubrir, como afirma Domínguez, "referentes pictóricos propios frente al modelo tutelar y académico de los italianos y los franceses" (Domínguez, 2003: 133). Esta autoestima que propicia el arte pronto pasó a formar parte de la reconfiguración nacional y patriótica que hizo frente a la ocupación napoleónica comenzada en 1801. A su vez, los acontecimientos históricos fortalecieron una idea de la pintura que alimentó el sentimiento de resistencia contra la ocupación francesa y su cultura, dando lugar al desprecio por la formación francesa que se había dado hasta entonces en las Academias de pintura alemanas. Es en este contexto en el que se forma un grupo de artistas especialmente interesados en unir arte y religión. Los promotores de este grupo fundaron en 1809 una especie de cofradía llamada La Liga de san Lucas (Lukasbund) ${ }^{6}$. Por su estilo de vida austero y sus largas melenas pronto se ganaron el apodo despectivo de "los Nazarenos". Los $\mathrm{Na}$ zarenos apostaron por resucitar la religión a través del arte. Defendían una pintura patriótica y cristiana, llegando incluso a adoptar una visión cultual del arte, según la cual el arte debía abandonar la búsqueda del esplendor formal para hablar directamente al corazón.

No podría entenderse la aparición de este tipo de ideas sin tener al mismo tiempo en cuenta el brusco giro que había supuesto en este sentido el protes-

${ }^{6}$ Los primeros componentes de este grupo fueron Johann Friedrich Overbeck y Franz Pforr, a quienes se unieron después Hottinger, Wintergest, Vogel y Sutter. Overbeck diseñó un emblema en el que aparecía san Lucas dentro de un arco con las siglas de cada uno de ellos (HWPOVS). La idea era que debía figurar en la parte trasera de todos los cuadros. A ellos se unirían más adelante otros pintores como Peter von Cornelius, Philipp Veit, Johann Heinrich Ferdinand von Olivier y Julius Schnorr von Carolsfeld (Honour, 1984). 
La primacía entre arte, religión y filosofía

tantismo. Más allá de la iconoclastia, la centralidad que el protestantismo otorgó desde sus comienzos a misterios como el de la Santísima Trinidad había implicado un fuerte viraje desde lo que habían sido las representaciones populares de santos y de imágenes marianas hacia la abstracción, y dificultó cualquier tipo de representación divina. De ahí que entre los pintores románticos se produjera un desplazamiento de las representaciones humanas hacia el paisaje con la intención de recuperar la espiritualización del arte. Puede verse esta búsqueda simbólica, por ejemplo, en las obras de Caspar David Friedrich en las que los personajes se ven superados por la inmensidad del paisaje, como en el caso de La Cruz en la montaña (1807) o El monje junto al $\operatorname{mar}(1809)$.

$\mathrm{El}$ anhelo trascendente está presente en toda la corriente romántica, pero a los Nazarenos no les bastará una espiritualidad abstracta como la que manifiesta Friedrich. Reclaman una sensibilidad tan concreta como la que busca volver a mostrar en los cuadros la vida de los pasajes narrados en el Antiguo y Nuevo Testamento ${ }^{7}$. Una gran convicción religiosa, unida a la pasión por la Edad Media y la pintura de Rafael, llevó a los Nazarenos a realizar una obra donde primaban, por encima de todo, los temas cristianos. Un ejemplo sobresaliente de su producción, la obra más importante y representativa, es $E l$ triunfo de la religión sobre las artes (1840), de Overbeck. Esta obra iba acom-

7 También en autores que no forman parte del grupo de "Los Nazarenos" pueden encontrarse ideas semejantes. A este respecto es interesante la obra La Cristiandad o Europa de Novalis, en la que se proyecta sobre la Iglesia católica la unidad espiritual en Europa, truncada con la aparición de la Reforma (Novalis, 2004: 97-120). 
pañada de un texto del propio autor en el que resumía todo el programa de renacimiento de la pintura cristiana. En él puede leerse:

Las artes son celebradas aquí sólo en la medida en que contribuyen a la glorificación de Dios y, de esta manera, forman una de las flores más delicadas con las que aparece adornada su Iglesia. (Overbeck, 1999: 165)

Como puede verse, el programa está aquí por encima del propio arte, la forma está al servicio del contenido, el qué por encima del cómo (Inciarte, 2016: 59). Este hecho tuvo como consecuencia que la obra de estos autores en su conjunto no alcanzara una gran calidad, y que fuese escasamente valorada y duramente criticada, especialmente por Goethe. Es cierto que esta "belleza cristiana" no se expresó en un nuevo estilo especialmente armónico o elegante. Lo que se buscaba defender no era tanto una elegancia formal, sino la belleza del espíritu cristiano que toma conciencia de sí. En este sentido, la naturaleza del nuevo arte es "ser un arte siempre anhelante, que no hace sino indagar en pos de la Idea suprema y es concebido como una perpetua búsqueda" (Schlegel, 1999: 137). Es decir, un arte inspirado por la devoción y que quiere mover a la devoción.

A pesar de la mediocridad de los resultados artísticos, la teoría pictórica y el programa de los Nazarenos fueron influyentes no sólo en su época, sino también más adelante, puesto que supusieron un desarrollo de una teoría del arte que pasaría a formar parte del arte contemporáneo. El incremento de carga filosófica que alcanzó esta corriente vino determinado por la relación que estos autores tuvieron con el ya citado círculo de intelectuales románticos del Athenäum. Los hermanos August (1767-1845) y Friedrich Schlegel 
La primacia entre arte, religión y filosofía

(1772-1829) fueron los verdaderos impulsores intelectuales de este grupo de artistas. Al primero le debemos el desarrollo de la idea que asimila el arte con la pintura. August Schlegel entra en la discusión abierta con Winckelman y afirma que, si bien el arte antiguo es un buen modelo de unión de arte y religión, no deja de representar el paganismo antiguo. Para la representación de la fe moderna es mejor la pintura, pues a través de ella la religión cristiana podría seguir explotando la sensualidad con la que el arte configura sus historias y mensajes, así como mover a la devoción de los fieles. Los Schlegel comprenden la vuelta a los temas y las formas medievales no sólo como una propuesta estética, sino como una revolución que es más importante desde el punto "de vista político que desde el punto de vista estético puro" (Domínguez, 2003: 129). Por esta razón, Friedrich Schlegel, tras convertirse al catolicismo en 1808, llevó a cabo toda una campaña política en defensa de los Nazarenos ${ }^{8}$.

Lo más importante de esta discusión sobre arte y religión, que quizá podría parecer marginal, es que tras ella se esconde un viraje esencial del romanticismo. Hasta entonces el romanticismo se había centrado en la nostalgia (Sehnsucht) de los temas y valores del pasado y en el intento de recrear ese pasado. Ahora, ese ideal se proyecta hacia el futuro. Ya no se trata de

\footnotetext{
${ }^{8}$ Aunque todos estaban de acuerdo en que la sensibilidad católica respondía mejor a sus teorías que la austeridad protestante, muchos de ellos no eran en su inicio católicos, como comenta D'Angelo: "Friedrich Schlegel y su mujer se convirtieron al catolicismo en 1808. Philipp y Jonas Veit lo hicieron dos años después. Overbeck se convertiría oficialmente en 1813. El «peligro de hacerse católicos» apuntado por August Schlegel en Las Pinturas ya no era una hipótesis, sino una realidad" (1999: 25).
} 
buscar los orígenes de la identidad, sino de definirla para tener un ideal que alcanzar como nación.

Este cambio que se cataliza alrededor de las discusiones sobre arte y religión hubiera sido inconcebible sin la concepción de la historia, que ya está en Fichte y también encontramos en A. Schlegel, como un "desarrollo dialéctico impulsado por el antagonismo entre naturaleza y libertad" (Sánchez Meca, 2013: 186). En este sentido, el debate que se genera en el seno del romanticismo sobre hacia dónde dirigir la mirada incrementa la conciencia que estos filósofos tienen de ser sujetos históricos. Pero no sólo eso, sino que además transforma la manera de entender la historia. El peso de la historia, en efecto, se traslada del pasado al futuro, por lo que se comienza a entender como el progresivo camino del espíritu hacia la libertad, perspectiva que más adelante será de vital importancia en la filosofía de Hegel.

Para que el contexto de la exaltación romántica del arte sea completo es imprescindible atender también a un tercer aspecto: la mistificación idealista del arte, el proceso en el que se llegan a considerar la razón estética —el arte- como el ámbito de reconciliación de la necesidad y la libertad.

\subsection{El lugar del arte en el sistema idealista}

En este tercer apartado abordaremos otro grupo de gran importancia en el romanticismo, el que redacta el Ältestes Systemprogram des Deutschen Idealismus (1796), el manifiesto del idealismo alemán. De esta obra solo queda una copia manuscrita por Hegel, escrita en primera persona, pero también se ha atribuido a Hölderlin y Schelling, y es posible que lo hicieran los tres en 
común ${ }^{9}$. En este breve pero intenso texto puede verse la vinculación que para ellos tiene la noción de mitología como algo racional con la opinión compartida sobre el arte como algo sublime ${ }^{10}$. Así, puede leerse en él que "el acto supremo de la razón, al abarcar todas las ideas, es un acto estético, y que la verdad y la bondad se ven hermanadas sólo en la belleza” (Hegel, 1984: 220). Es aquí también donde aparece la poesía como culminación del arte, como síntesis final que asume el inicio: "La poesía recibe así una dignidad superior y será al fin lo que era en el comienzo: la maestra de la humanidad" (Hegel, 1984: 220).

De entre los tres amigos, quien se acercó con más profundidad a la cima que representaba la poesía fue Hölderlin, pues sólo él la cultivó y dedicó su vida a desarrollarla en obras de creación. Una de las mejores muestras de su profunda filosofía poética es la novela Hiperión o el eremita en Grecia (1797), en la que el protagonista sueña una y otra vez con revivir el mundo griego ya inexistente, un mundo que representa la unidad con la naturaleza frente al

\footnotetext{
${ }^{9}$ Aunque ciertamente la autoría de esta obra no es del todo clara, Madureira ha puesto de manifiesto que en los escritos de juventud de Hegel el arte siempre está incluido en la religión, debido a que ambos comparten el componente sensible y la función estetizante, por lo que muy bien podría asumir lo que se dice en el Systemprogramm (Madureira, 2009: 47-48).

${ }^{10}$ La mitología a la que se alude aquí es de orden filosófico. Se trata de que esta nueva mitología "haga sensibles las ideas y la razón, que las exprese estéticamente y, por medio de la belleza, las convierta en algo sentido, vivido (...); se exige una nueva simbología fundante que se ponga al servicio de las ideas de la razón y de la libertad a las que ha llegado el Idealismo (Kant y Fichte) realizando la síntesis de éstas con nuestra finitud y facticidad" (Rivera de Rosales, 2001: 425).
} 
sistema mecánico del Estado moderno, en el que ya no hay lugar para los dioses. Muestra cómo Hölderlin, tanto en su poesía como en sus escritos sobre religión trata de recuperar el espacio de lo divino. Y para él lo divino no se manifiesta a través de la memoria - historia - ni del pensamiento filosofía-, sino a través de la imagen poética. Como recuerda Jamme, frente a las posiciones de los idealistas que consideraban que Dios era lo encubierto que se iba revelando, para el poeta Dios no se revela nunca por completo. Por esa razón sólo puede entreverse en las creaciones poéticas (Jamme, 1999: 5174).

Dada la estrecha relación que durante el romanticismo hubo entre todos los ámbitos artísticos es fácil imaginar que fuera Hölderlin quien moviera a Schelling y al círculo de Jena a interesarse por el arte. A su vez, Schelling desarrolló de tal manera la relación entre filosofía y arte que se convirtió en el filósofo de los artistas románticos, especialmente por la importancia que otorgó a la intuición y la fantasía ${ }^{11}$. De todos modos, es necesario aclarar que, a pesar de que la mistificación del arte fue asumida por muchos de los integrantes de esta generación, es necesario distinguir el grupo que se constituye alrededor de Schelling del núcleo de los filósofos y poetas que dieron cuerpo al idealismo. Si bien ambos grupos pertenecen a la misma generación, beben

${ }^{11}$ Así lo defiende Gabás: "Hölderlin y el círculo romántico despertaron en Schelling el interés estético, y fue considerado como el filósofo del romanticismo por la importancia que concedía a la intuición, a la fantasía creadora, al instinto y a lo irracional, y por su insistencia en el universo como totalidad viviente. Compartía además el ideal romántico de elaborar una creación poética que albergase todo el universo" (Gabás, 2012: XVII). 
La primacia entre arte, religión y filosofía

de las mismas fuentes y ahondan en los mismos temas, se diferencian en que los primeros hacen un gran énfasis en el sentimiento y la imaginación, mientras que los autores del idealismo alemán no se desembarazan en ningún momento del poder especulativo de la razón. Matiz esencial para determinar en cada grupo qué esfera debe ostentar el grado más alto en el sistema filosófico.

El grupo de los seguidores de Schelling defendía que la naturaleza tiene una estrecha relación con el arte, ya que ambos parecen ser producto de una fuerza creadora inconsciente. De ahí que vieran el arte como el lugar de reconciliación y unidad de la naturaleza y del hombre. Schelling considera que la naturaleza no puede ser ajena al espíritu y, por tanto, si entendemos la fuerza que está operando en la naturaleza, entenderemos el espíritu. De esta razón se deriva no sólo que el infinito se manifiesta en la naturaleza finita, sino que esta es uno de los lugares a través de los cuales el ser humano puede alcanzar lo infinito. De ahí la importancia del arte: como la tensión entre lo infinito de la conciencia y lo finito de lo natural no es tematizable, queda expresamente reservada al arte, puesto que, como explica Inciarte en La imaginación trascendental, "sólo el arte consigue, gracias a la imaginación creadora, reconciliar lo irreconciliable, sintetizar lo finito con lo infinito, la consciencia con la inconsciencia" (2012: 73) ${ }^{12}$.

12 Por otro lado, Inciarte también insiste en que "el abandonar la razón, el intelecto, la humanidad y, con ello, la finitud o la realidad y aceptar hundirse (...) en el abismo de lo subconsciente, es precisamente lo que nos abre a lo infinito, al fondo de nuestro verdadero ser en la absoluta indiferencia” (2012: 75). 
En 1800 Schelling publicó Sistema del idealismo trascendental, una obra en la que intenta superar las aporías en las que se estaba quedando encerrada la filosofía durante estos años. Al contrario de lo que luego veremos en Hegel, en su sistema el arte ocupa el lugar más alto de la tríada arte, religión y filosofía, pues "sólo a él le puede ser dado satisfacer nuestro esfuerzo infinito y solucionar en nosotros la contradicción última y extrema" (Schelling, 1988: 130). Esto se entiende mejor si se tiene en cuenta que para Schelling la intuición intelectual que está en juego en la filosofía sólo reconoce lo que se sabe, mientras que el arte aporta la identidad de lo subjetivo y objetivo ${ }^{13}$. En este sentido, el arte eleva al hombre al conocimiento supremo por encima de dualidades, y por eso es el terreno de la libertad. El arte es el obrar libre en el que se resuelven las contradicciones. De ahí que la figura que encarna la libertad en el arte no pueda ser otra que la del genio, pues él produce desde la subjetividad pero con libertad ${ }^{14}$. La figura del genio se desarrollará con fuerza a

${ }^{13}$ A este respecto, Schelling afirma: "Retira del arte la objetividad y entonces deja de ser lo que es y se convierte en filosofía. Dale a la filosofía la objetividad, y entonces deja de ser filosofía para convertirse en arte. La filosofía alcanza ciertamente lo supremo, pero eleva a este punto sólo un fragmento del hombre. (...) El arte eleva al hombre entero tal y como es al conocimiento de lo supremo, y sobre esto reposa la diferencia eterna y el milagro del arte" (Schelling, 1988: 141).

14 "Sólo en el arte puede aparecer el genio, capaz de resolver por la intuición una contradicción que de otra forma hubiera sido irresoluble, incluso en contra de la voluntad del hombre en quien se presenta la genialidad" (López y Rivera de Rosales, 1988: 88). Mientras que en Schelling la libertad está personificada en la figura del genio como aquel que actúa sin determinaciones, para Hegel la libertad no es más que el conocimiento de la necesidad. Un planteamiento mucho más spinozista, que Schelling trata de superar. 
partir de esta época porque encarna la auténtica subjetividad libre ${ }^{15}$. Schelling considera también que, si con la obra de arte se puede explicar cómo lo infinito puede manifestarse en lo finito, de manera similar el ser humano podrá alcanzar lo que para él sería imposible: la infinitud. Por todo ello, el arte se le presenta con un carácter de totalidad superior a la filosofía.

Volviendo a las relaciones entre arte, religión y filosofía, es necesario destacar la convicción de Schelling de que parte de la misión que la filosofía y el arte deben cumplir en el mundo moderno es la que tuvo la mitología en tiempos antiguos, una función religiosa. Al final de su obra Filosofía del arte presenta la unión del arte con la religión como la solución a las divisiones que ha provocado el mundo moderno. Habla de un "lazo íntimo que une el arte con la religión", de la "imposibilidad de dar al arte un mundo poético distinto del que existe dentro de la religión" y de "la imposibilidad de llevar la religión a una manifestación verdaderamente objetiva que no sea la del arte" (Schelling, 1999: 505). Debido a esta importancia crucial, también la política debería considerar el arte como el mejor aliado para la renovación de la vida pública. De hecho, para Schelling incluso el mismo Estado debería considerarse como una obra de arte:

Si tampoco se pudiese llegar a comprender en general que el arte es una parte necesaria e integrante de una constitución de Estado proyectada según ideas,

${ }^{15}$ Por esta razón, más adelante se empezará a extender la idea de que su expresividad no tiene que ver con una ninguna revelación sino que es completamente arbitraria. Los artistas de siglo $\mathrm{XX}$, en su mayoría, rechazarán la idea de "genio" y apostarán por un cambio en la visión del artista mucho más abierto y democrático. 
Raquel Cascales

debería recordarlo al menos la Antigüedad, cuyas fiestas universales, monumentos perpetuos, espectáculos, así como todos los actos de la vida pública, sólo eran las distintas ramas de una única obra de arte general, objetiva y viviente. (Schelling, 1999: 505)

Esta argumentación muestra una máxima exaltación y mistificación del arte, que parece colocarlo en el lugar superior de la existencia. Sin embargo, Hegel demostrará muy pronto que lo que tras estas palabras se esconde es, en realidad, la convicción de que el arte debe estar a merced de otros intereses como la religión o la política. Hegel estará de acuerdo con Schelling en la importancia de valorar del arte, por su influjo en la cultura y por su importante papel en la formación (Bildung) del espíritu de los ciudadanos, pero discrepará con él no sólo en el alcance en la satisfacción, sino también en el propio modo de entender el arte (Pöggeler, 1956) ${ }^{16}$.

Ya en las primeras páginas de las Lecciones de estética encontramos una dura crítica a una consideración del arte que lo deje en función de intereses ajenos a él. Hegel refuta los planteamientos que consideran el arte algo ocioso, superfluo, lujoso, inútil, que fomenta el ocio, la frivolidad y, además, se vale del engaño y la apariencia. También rechaza la concepción del arte como objeto de la sensación, de la intuición o de la imaginación pero no de la razón. Considera que quienes lo ven así le otorgan aparentemente un espacio

${ }^{16}$ Se debe entender Bildung como el ideal decimonónico del hombre hecho a sí mismo, de la autorealización, fruto de un conocimiento íntimo y una vida de pleno sentido. 
La primacia entre arte, religión y filosofía

de libertad desde el cual el arte podría cumplir la noble función de formar el espíritu y educar moralmente — sería el caso de Schiller-, pero olvidan que esta perspectiva convierte al arte en un mero instrumento a favor de otros fines. Hegel demuestra cómo en el fondo esta consideración del arte es servil y la rechaza.

Esto no quiere decir que para él el arte sea secundario. A lo largo de la historia se le habían atribuido muchos fines nobles al arte, pero nunca se le había colocado en una posición tan elevada ni había jugado un papel tan determinante como el que protagoniza en el sistema hegeliano. Hegel simboliza este papel fundamental con la figura de un puente en el que la mitad del arco corresponde a la historia universal —el espíritu objetivo- y la otra mitad al arte, que se encuentra ya formando parte del espíritu absoluto. El arte se sitúa en el lugar más alto y es capaz de expresar el espíritu absoluto. Como él mismo dice,

...por primera vez en esta libertad es el arte bello verdaderamente arte, y sólo resuelve su tarea suprema cuando se sitúa junto con la religión y la filosofía, convirtiéndose en una forma de hacer consciente y expresar lo divino, los intereses más profundos del hombre, las verdades más universales del espíritu (Hegel, 1989: 14).

Aunque esta consideración del arte podría parecer muy similar a la de las tesis principales del romanticismo, el hecho es que la estética de Hegel, como acabamos de ver, se opone frontalmente a ellas. Hegel también se distingue del romanticismo por considerar que ni el mito ni el arte pueden valer como instancia de conciliación y unificación. Este papel le corresponde únicamente 
a la razón, que debe rectificar su unilateralidad como pura razón analítica y convertirse en razón absoluta (Sánchez Meca, 2013: 167).

Además, Hegel también se distancia del idealismo de Fichte y Schelling al considerar que el verdadero infinito solo puede ser el que, en la realidad, realiza su propia infinitud superando todo lo finito. Considera que no basta la manifestación en lo finito si luego este no queda superado. Sólo es verdaderamente real el infinito que ha incorporado en sí todos los momentos finitos. Por tanto, es la filosofía como máxima expresión de la razón, y no en el arte, el lugar donde se toma conciencia de la unidad de la realidad. El arte es la forma sensible en la que el absoluto se aprehende a sí mismo intuitivamente, pero esta forma no es la más elevada. De ahí la necesidad que tiene de mostrar cómo se puede superar la mistificación del arte a través de la filosofía.

\section{La superación de la mistificación del arte}

\subsection{Arte, religión y filosofia en Hegel}

Como se ha visto, el romanticismo exaltó el arte y le confió la formación espiritual de los individuos hasta convertirlo prácticamente en una religión. Hegel, sin embargo, a pesar del lugar preeminente que le otorga en su obra, va a delimitar su alcance. Lo hará de manera progresiva, y puede verse cómo evoluciona su pensamiento al respecto a lo largo de sus distintas obras filosóficas. De hecho, la relación entre arte y religión configura gran parte de la cohesión de las distintas obras en las que Hegel trata el arte, y aporta luz 
La primacia entre arte, religión y filosofía

sobre el lugar del arte en el espíritu absoluto, así como sobre su estatuto a la vez histórico y transhistórico.

Hegel considera que el espíritu se ha expresado a lo largo de la historia de manera adecuada a través de las obras de arte. Las obras de arte han servido para representar a las divinidades, y por tanto han permitido a los seres humanos mantener una relación directa e intuitiva con lo divino. Relacionarse con lo divino consistía en relacionarse con la representación que se hubiera forjado, ya estuviera unida al mundo natural, animal, humano o sobrenatural. La expresión de este desarrollo histórico se recorre en la Fenomenología del espiritu a través de tres diferentes etapas.

La primera de ellas, que no trataré aquí, es la religión natural de las tradiciones persa, india o egipcia. Son culturas en las que no hay propiamente arte sino artesanía, lo cual implica una ausencia de lenguaje que a su vez manifiesta una falta de interioridad.

En la segunda etapa, la de la religión del arte, es donde se produce el encuentro del espíritu con su forma de conciencia correspondiente. Mediante la religión del arte, el espíritu se objetiva y se pone frente a sí, es capaz de distinguirse y, a la vez, de reconocerse en su obra. A través de este salir de sí, el espíritu reflexiona sobre sí mismo, se sabe para sí a través de la figura del arte históricamente instalada en el tiempo. Hegel llama a este momento "religión del arte" quizá por la fuerza que dicha expresión había tomado en el romanticismo, como he explicado anteriormente. Sin embargo, marca una importante distancia con la concepción romántica, pues la religión del arte está destinada en su obra a ser superada por la verdadera religión, la religión 
revelada. Solamente con el cristianismo se abre totalmente la subjetividad y el espíritu puede contemplarse verdaderamente a sí mismo.

Durante la etapa de la religión del arte, la conciencia del creyente esta todavía en búsqueda de la forma que le corresponde. Se expresa a través del culto, en el que Hegel reconoce la ruptura de la armonía que se presentaba en el espíritu ético, la desarmonía de la verdad de un ser con su certeza, la traición de la sustancia que al tomar demasiada conciencia se transforma en sujeto. De hecho, el espíritu que retorna aquí, en el culto, es el espíritu objetivo (eticidad, cultura y moralidad), aunque se aluda a él mediante su primera forma, el espíritu ético. Retorna a sí de forma autoconsciente y activa para que, mediante la actividad del artesano, surja como objeto y con ello resurja el espíritu moral.

El paso del artesano inconsciente a la autoconsciencia del artista permite la aparición de la obra de arte: en este proceso se pasa del arte cósico y falto de espíritu de la religión natural — que puede ejemplificarse en las pirámides egipcias-, al arte plástico de la religión del arte manifestado en Grecia. Dentro de la religión del arte, Hegel reproduce de algún modo los tres estadios de la religión concretándolos en objetos, en las obras de arte. El primero está formado por un arte abstracto, objetivo, representado por la escultura; el segundo, por un arte viviente donde se unen lo humano y lo divino en los juegos olímpicos; el último, por un arte espiritual, representado por el teatro, donde se hace presente la conciencia desgraciada y se da paso a la religión revelada.

La religión del arte alcanza su propósito cuando el espíritu se ha despojado de una figura que le resultaba extraña — la de la estatua, la bella 
corporalidad o las representaciones poéticas - produciendo su propia figura para llegar a tener conciencia de sí. El pasado queda atrás, pero es lo que permite al espíritu llegar a ser consciente de sí mismo como espíritu. Esta transformación supone el paso a la tercera etapa de la religión, el cristianismo.

La religión revelada es el último momento y figura culmen del espíritu. Acabamos de ver que la religión del arte mostraba una unión perfecta entre el espíritu y su expresión, por lo que la conciencia podía reconocer la divinidad en la forma artística. Aunque la conciencia estaba dichosa en esa contemplación, su unión era superficial. Frente a la religión del arte, la religión revelada supone la revelación de un Dios que se ha encarnado y ha entrado en la historia. Su cuerpo no es una representación de la divinidad, sino la misma divinidad ${ }^{17}$. Ahora ya no hay ninguna expresión artística capaz de expresar esta realidad, pero ya no la necesitamos:

Las estatuas son ahora cadáveres cuya alma vivificadora se ha esfumado, así como los himnos son palabras de las que ha huido la fe; las mesas de los dioses se han quedado sin comida y sin bebida espirituales y sus juegos y sus fiestas no infunden de nuevo a la conciencia gozosa unidad de ellas con la esencia. A las obras de la musa les falta la fuerza del espíritu que veía brotar del aplastamiento de los

17 "El sí mismo del espíritu que es allí tiene de este modo la forma de la perfecta inmediatez; no se pone ni como pensado o representado ni como producido, como ocurre con el sí mismo inmediato, en parte en la religión natural y en parte en la religión del arte, sino que este Dios deviene inmediatamente como sí mismo, como un real hombre singular sensiblemente intuido; solamente así es autoconciencia” (Hegel, 2004: 436). 


\section{Raquel Cascales}

dioses y los hombres la certeza de sí mismo. Ahora, ya sólo son lo que son para nosotros — bellos frutos arrancados del árbol [...]—; ya no hay ni la vida real de su existencia, ni el árbol que los sostuvo, ni la tierra y los elementos que constituían su sustancia, ni el clima que constituía su determinabilidad o el cambio de las estaciones del año que dominaban el proceso de su devenir. El destino no nos entrega con las obras de este arte su mundo, la primavera y el verano de la vida ética en las que florecen y maduran, sino solamente el recuerdo velado de esta realidad (Hegel, 2004: 436).

Como puede verse en el texto el hombre moderno autoconsciente ya no es capaz de contemplar vida en las obras de arte. De hecho, este cambio de sensibilidad tendrá consecuencias en diferentes órdenes. Por ejemplo en el ámbito ético: puesto que las obras de arte pueden hacernos recordar épocas pasadas, y ya no creemos que haya manifestación de la divinidad en ellas, los problemas morales con los que se enfrentaban los griegos cuando adoraban a los dioses se relegan ahora a la propia conciencia (Jamme, 2010: 202-203) ${ }^{18}$.

\footnotetext{
${ }^{18} \mathrm{Al}$ menos esto puede decirse en lo que corresponde a la visión artística occidental. Claro está que ha sido la mayoritaria en Europa y es en cualquier caso la que está manejando Hegel. Un caso distintito sería la consideración que en Oriente se tiene de los iconos, tal y como Inciarte pone de manifiesto (2016: 49-55). Por otro lado, también puede señalarse que el hecho de que las obras ya no sean algo vivo es uno de los motivos que genera su reclusión y clasificación taxonómica en los museos. Podría hacerse una correlación entre el espíritu ilustrado francés, científico y democratizante, fruto del Nuevo Régimen, y la apertura de los primeros museos públicos, como el Museo del Louvre. Que se expusieran por primera vez en sus salas las obras que simbolizaban el Antiguo Régimen era de algún modo una forma de manifestar que este ya formaba parte del pasado (Jiménez Blanco, 2014: 78-90).
} 
Así pues, en este somero repaso a la Fenomenología del espíritu vemos que en ella el arte se ve superado por la religión revelada, que aparece como una esfera más profunda, más adecuada al espíritu.

La postura que presenta Hegel en la Fenomenología irá evolucionando en obras posteriores. En la Enciclopedia de las ciencias filosóficas el arte ocupa también un estadio todavía inicial en el despliegue del espíritu. Sin embargo, en ella se advierte que está experimentando un cambio de posición dentro del sistema hegeliano: de ser una figura dentro de la religión pasa aquí a constituir el primer estadio autónomo dentro del espíritu absoluto. De este lugar que ocupa en el interior del espíritu absoluto, así como de las implicaciones que esto tiene, es de lo que hablará Hegel en las Lecciones de estética.

Las Lecciones de estética son la obra madura del pensamiento hegeliano. En ellas, como veíamos, en ellas el arte se encuentra en el ámbito del espíritu absoluto, lo cual supone que Hegel inscribe al arte en el ámbito de la conciencia, la libertad y la verdad. En efecto, es en él donde se da una mayor coincidencia entre la racionalidad del pensamiento y su expresión. Tanto el arte como la religión y la filosofía comparten el mismo contenido, la idea o verdad. Se diferencian en la forma con la que cada una hace presente ese contenido. Ese hacer presente también implica diferencias en nuestra manera de captar la verdad. En este sentido, lo propio del arte es su expresión sensible, que captamos como intuición sensible (Anschaunng). La religión, por su parte, es pura interioridad y el medio a través del cual la captamos es la representación (Vorstellung). La filosofía, por último, culminación del proceso, es la expresión más racional del sistema y, por ello, se sirve del pensar puro (Denken): "El pensamiento penetra en la profundidad de un mundo supra- 
sensible, y lo presenta primeramente como un más allá a la conciencia inmediata y a la sensación actual" (Hegel, 1989: 14).

Dentro de esta obra, Hegel vuelve a establecer una triple división formal que se corresponde con los distintos momentos del despliegue histórico del arte. Así, al arte simbólico egipcio le corresponde la arquitectura y al clásico griego la escultura. El tercer estadio es el despliegue del arte romántico, que coincide con la primacía de la interioridad que adviene con la religión protestante y con el desarrollo de la modernidad misma ${ }^{19}$.

Aunque este tercer momento debería corresponder a la perfección que supone la religión revelada, el arte romántico se caracteriza por un nuevo desequilibrio entre forma y contenido, en el que la forma pierde relevancia frente al contenido. $\mathrm{El}$ espíritu romántico parece recrearse en un exceso de contenido que provoca el desequilibrio, pues de algún modo muestra una "superioridad" espiritual ${ }^{20}$, que lleva a algunos autores a hablar de un nuevo simbolismo (D'Angelo, 1989: 179-234). Sin embargo, a diferencia del momento simbólico clásico, ahora no es la forma sino el contenido el que se

${ }^{19}$ Pinkard vincula el desarrollo del arte romántico con el desarrollo de la modernidad a partir del principio cristiano de la interioridad. " $\mathrm{El}$ «verdadero contenido del arte romántico — decía Hegel- es la interioridad», y el contenido del arte está por ello abierto a una extensión infinita de su materia, a una «multiplicidad sin fronteras»" (Pinkard, 2001: 751).

20 "El arte romántico, por causa de la espiritualidad libre de su contenido, exige más de lo que es capaz de ofrecer la representación en lo exterior y corporal. Por eso la forma se convierte en una exterioridad más indiferente, de modo que el arte romántico introduce de nuevo la separación entre contenido y forma, si bien desde un lado opuesto al del arte simbólico” (Hegel, 1989: 265). 


\section{La primacía entre arte, religión y filosofía}

desborda. El contenido espiritual que el cristianismo trae supera no sólo la forma clásica, sino cualquier forma artística: "El verdadero elemento para la realidad de este contenido ya no es la inmediata existencia sensible de lo espiritual, la forma corporal humana, sino la interioridad consciente de sí misma" (Hegel, 1989: 74).

Ahora lo importante ya no es el objeto en sí, pues este ya no muestra el equilibrio de las formas clásicas, sino el contenido, que acoge las grandes verdades cristianas y, al mismo tiempo, expresa la interioridad individual del artista. Por esta razón, las artes menos materiales como la música y la poesía jugarán un mayor papel en esta época ${ }^{21}$. De hecho "la poesía es elevada a arte supremo por el romanticismo y llega a ser considerada por Hegel como la verdad del arte" (Cubo 2010: 15). De algún modo la poesía se verá abocada a ir más allá de sí misma. En este sentido, el exceso de interioridad y subjetividad románticas desembocarán una vez más en la necesidad de superar este estadio.

Por paradójico que parezca, la sobreabundancia de contenido espiritual va a tener como consecuencia que el arte ya no satisfaga nuestras necesidades

${ }^{21}$ La clasificación que hace Hegel de las formas artísticas tiene el siguiente orden: arquitectura, escultura, pintura, música y poesía. Obedece a la manera en la que expresan el espíritu, y por eso en esta división se muestra una tendencia hacia la desmaterialización o espiritualización del arte, que a su vez corresponde con la interiorización de las artes: mientras que la arquitectura es lo más externo y "vacío", pues consiste en crear espacios, la poesía es una forma interiorizada, y cabe entenderla en el interior del espíritu. 
espirituales. Esto es así porque el desarrollo del arte ha comportado un desarrollo del espíritu, que ahora busca otras esferas de comprensión. Con este razonamiento, Hegel acaba derribando la veneración romántica por la significatividad y la libertad de la obra de arte "puesto que nos habla de la superación del momento del Arte que ya no tiene capacidad para expresar nuestras necesidades espirituales" (Ramírez, 1988: 128). La relevancia de este planteamiento es patente. De la religión como arte se ha pasado a un arte trascendido por la religión, que ahora comparece como una forma mejor de expresar y hacerse cargo de la interioridad y el sentimiento humano, así como de orientarle hacia la libertad. Debido a este rebasamiento, el arte ya no está obligado a representar lo divino y, en este sentido, se "libera" y desacraliza. Este horizonte desacralizado abre el arte a todos los contenidos que inquietan el corazón humano. $\mathrm{El}$ arte, en este sentido, ha ido para Hegel "más allá de sí mismo" y, al mismo tiempo, ha retornado sobre sí. Se trata de

...un descender a su propio pecho, con lo cual el arte borra toda limitación fija a un determinado círculo del contenido y de la concepción del mundo, para convertir en su nuevo santuario lo humano (Hegel, 1989: 171-172).

Es precisamente esta postura la que permite que, a partir de ese momento, "lo humano", con sus inquietudes, sus grandezas y miserias, se convierta en el contenido del arte. Esta es también la razón de la preponderancia que el artista va a adquirir en la cultura moderna del arte:

Con ello el artista recibe el contenido en él mismo y es el que realmente se determina a sí mismo, es el espíritu humano, el que considera la infinitud de sus 
La primacía entre arte, religión y filosofía

sentimientos y situaciones, reflexiona sobre ellos y los expresa, un espíritu humano al que no es extraño nada de lo que puede estar vivo en el corazón del hombre (Hegel, 1989: 172).

Así pues, el arte se desprende de su contenido religioso, de su unión con lo sagrado, y el artista puede ahora centrar su mirada en lo particular y en lo cotidiano. La creatividad artística, en especial en el ámbito del contenido o la temática, se amplia enormemente. En virtud de esta “secularización”, la mirada artística se va fijando de forma progresiva "en el mundo, en los hombres $\mathrm{y}$ sus pasiones, sobre todo en el amor, en donde interesa el individuo como pasión particular, y no la constitución de la comunidad ética" (Rivera de Rosales, 2011: 107). Pero, paradójicamente, en la medida que el arte gana esa autonomía parece perder la posibilidad de ser una esfera de comparecencia de la verdad, lo cual lleva una cierta relativización de todas las artes ${ }^{22}$.

Por otro lado, una vez el espíritu ha superado su expresión sensible se ha percatado de que la verdad del arte no está en el arte, de modo que ahora puede preguntarse acerca de qué es la esencia y la verdad del arte. Hegel, de

${ }^{22}$ Houlgate defiende: "The emancipation of the secular and the human in art marks the liberation of art itself from religion. But his autonomy is acquired at a price, Hegel believes, because in being separated off from religion art loses its equality with religion as the full revelation of the highest truth" (1991: 167-168). De la misma opinión parece Desmond cuando afirma que "esta mayor libertad subjetiva significa para Hegel la pérdida de fundamentos sustanciales y así una pérdida de seriedad espiritual para el arte" (2007: 45-46). De hecho, también el tiempo ha mostrado que esta libertad ha llevado consigo una reducción del arte al ámbito privado, en el que corre el riesgo de ser sometido a otros intereses, en este caso de la industria y el mercado. 


\section{Raquel Cascales}

hecho, deja claro que, una vez superado este momento, podremos tematizar qué es el arte desde el punto de vista filosófico, ahondar en la esencia del arte. En este sentido se lee:

Lo que ahora despierta en nosotros la obra de arte es el disfrute inmediato y a la vez nuestro juicio, por cuanto corremos a estudiar el contenido, los medios de representación de la obra de arte y la adecuación o inadecuación entre estos dos polos. [...] El arte nos invita a la contemplación reflexiva, pero no con el fin de producir nuevamente arte, sino para conocer científicamente lo que es el arte (Hegel, 1989: 17).

Sin embargo, esa esencia sólo se va a encontrar atendiendo al contenido del espíritu a través del estudio filosófico y, por tanto, científico. La obra de arte, en la que se aliena el pensamiento, "pertenece también al ámbito del pensamiento conceptual; y el espíritu, en cuanto la somete a la consideración científica, no hace sino satisfacer en ella su naturaleza más íntima” (Hegel, 1989: 19). Pero analizar científicamente el arte no es hacer arte, sino que se está ya en el orden que trata de explicar qué son las realidades y no en el mero llevarlas a cabo.

En cualquier caso, si antes el hombre esperaba del arte la verdad suprema, ahora para conocer esa verdad o bien acude a la ciencia o bien desciende al interior de su propio pecho. Ni siquiera parece que se busquen ya las enseñanzas morales en las representaciones artísticas, ni que las sociedades estén fundadas en narraciones mitológicas, sino que las vinculaciones modernas exigen un grado de racionalidad mayor. 
En este sentido, parece obvio también que el arte ya no está supeditado a los intereses religiosos ni a mostrar la verdad de la religión. Tampoco cumple la función de unificar conciencias, ni de suscitar sentimientos que otorguen una unidad política y social. Visto del lado de la religión, también cabría decir que los contenidos de la religión cristiana exceden la sensibilidad artística. Sin embargo, eso no significa que el arte no pueda seguir hablando de lo religioso o lo sagrado. De hecho hay algunos autores que consideran que el arte está lejos de ocupar un lugar secundario en la vida espiritual del hombre moderno. A este respecto Charles Taylor afirma que el arte ha sustituido a la religión en muchos de nuestros contemporáneos, "en el sentido en que es para ellos la más alta expresión de lo que tiene importancia última, y/o de la actividad superior del hombre" (Taylor, 2010: 417). Desde esta visión, por tanto, sería el arte el que ha reemplazado a la religión. No obstante, cabe señalar una vez más que el ámbito en el que Hegel considera que se puede dar cuenta de la realidad y acabar con las diferentes tensiones mencionadas entre arte, religión y política es el pensamiento racional. Más en concreto, es la filosofía la que está destinada a dar cuenta de todo lo real, incluido, por supuesto, el arte.

Parece, por tanto, que Hegel cierra el círculo y con él queda dicho todo. No obstante, me gustaría reseñar a modo de coda, la respuesta que Fernando Inciarte hace a Hegel en este punto. Aunque Hegel consideraba que en los tiempos venideros la reflexión sobre el arte vendría del seno de la filosofía, lo que no podía llegar a imaginar era el carácter reflexivo que llegaría a alcanzar el arte. Lo interesante de la respuesta de Inciarte a Hegel no es que vuelva a 
colocar el arte por encima de la religión o la filosofía, sino que diluye la tensión dialéctica fuera del sistema tríadico, en la vida.

\subsection{Inciarte y la primacía de la vida}

Tanto la mayor conciencia artística como la propia tematización del arte condujeron a finales del siglo XIX a que el arte se cargara de reflexión teórica e intelectual. En las representaciones artísticas de la contemporaneidad el desequilibrio del contenido con respecto a la forma cada vez se iba haciendo mayor. De ahí que el propio Inciarte considerara que esta reflexividad es uno de los rasgos más característicos del arte contemporáneo. Así lo explica:

El carácter reflexivo del arte moderno, a diferencia del arte tradicional, fue proféticamente anticipado por Hegel ya mucho antes de que apareciera en el curso de la historia. [...] Implícito en ese diagnóstico queda el hecho de que el arte ya había sustituido antes a la religión en ese lugar privilegiado. $\mathrm{Y}$ así como en la jerarquía de los intereses de la humanidad el arte sustituyó en el Renacimiento de hecho a la religión, así la filosofía sustituiría pronto a su vez al arte; de manera que lo que se convertiría en el futuro en la cuestión más viva con respecto al arte sería la pregunta sobre lo que sea el arte. Hasta ahí la profecía de Hegel. Lo que Hegel no llegó a predecir es que no iba a ser tanto la filosofía como el arte mismo el que, con el tiempo, iba a llevar a cabo ese trabajo reflexivo convirtiéndose de algún modo él mismo en filosofía del arte (Inciarte, 2001: 131).

Aquí encontramos una vuelta de tuerca más, pues ya no se trata de que Hegel, como señala Inciarte, adelantara que el arte se volvería cada vez más reflexivo, sino de que el arte "justamente en sus manifestaciones superiores se 
ha convertido repetidamente en filosofía del arte" (Inciarte, 2004: 74). Por eso defiende que el arte se ha convertido en filosofía del arte especialmente a partir de las vanguardias históricas. Es entonces cuando se rompe con el criterio de la mímesis convirtiendo el "parecido razonable" en irrelevante, y cuando se plantea, en cambio, el problema de la esencia del arte (Inciarte, 2001: 107).

Esta búsqueda de la esencia tiene dos rasgos característicos: simplificación y pureza. La primera supone la eliminación de cualquier elemento narrativo dentro de la representación pictórica, el despojamiento de toda ornamentación hasta llegar al máximo abstraccionismo. La segunda, que va en la misma línea pero es más radical, hay que entenderla en el sentido kantiano de pureza, que consiste en "una reflexión que empezó por sacar a la luz del día lo que hasta entonces se había intentado ocultar en pintura — sus mismos instrumentos [...] - y que terminó en la pura superficie y el puro color de tantos representantes del expresionismo abstracto” (Inciarte, 2001: 109).

Mientras que el arte tradicional o representativo había hecho hincapié en el qué (en el contenido) el moderno lo pone en el cómo (en el modo o la forma). En el arte de vanguardia, a diferencia de la pintura de "Los Nazarenos" — que sería típica del arte tradicional一, el contenido no cuenta tanto como la forma. Pero precisamente es en el cómo, en la forma, donde para Inciarte recae la importancia, pues es la forma la que determina el contenido, es en la forma de expresar donde te juegas lo expresado. Por eso Inciarte valora tanto el arte icónico y el de vanguardia, porque los dos, precisamente por el peso otorgado a la forma, expresan sin necesidad de decir. De ahí que ambos nos aporten grandes enseñanzas sobre el temple vital. 
El gran interés por el arte y su valoración positiva podría conducirnos erróneamente a pensar que, por tanto, para Inciarte el arte es lo más importante. Sin embargo, en Cultura y verdad puede verse que no es así. En concreto, Inciarte comienza exponiendo la tensión existente entre el ser artista (ser del mundo) y ser cristiano (rechazo del mundo). Esta tensión podría traducirse aquí por la pregunta sobre si es más importante el arte o la religión. Para hacerla más explicita, expone dos posturas enfrentadas entre sí: la de los arameos monofisistas y de los arameos nestorianos. Los primeros rechazaron la humanidad de Cristo, apostando sólo por la divinidad, lo cual llevó consigo que se desentendieran por completo de la cultura hasta el punto de que "a lo largo de toda su historia, ni tan siquiera se habían decidido a crear un Estado o una comunidad política” (Inciarte, 2016: 38). Por su parte, los segundos rechazaron la divinidad quedándose sólo con la humanidad, lo cual llevó consigo que "se lanzaron desde un principio en los brazos de la cultura abandonándose sin reparo a ella" (Inciarte, 2016: 41).

Aunque la filosofía de Inciarte nunca es taxativa y cerrada, mediante la explicación de estas dos posturas nos señala, en primer lugar, el peligro de abandonarse en brazos de la cultura, de pensar que el arte es lo más importante, que lo temporal es lo único eterno. Inciarte defiende que, por el contrario, no sólo de cultura puede vivir el hombre. En este sentido, el arte no está por encima de la vida, aunque tampoco está separado de ella. El arte es más bien como un concentrado de vida que nos permite comprender de 
manera intuitiva algunas realidades que no podemos captar de otro modo ${ }^{23}$. Pero quedarse meramente en eso sería un error. De ahí que señale la importancia de no quedarse en la obra de arte, ni siquiera en el arte en general, sino de vivir. El arte enseña a ver la vida despojada de su carácter aparencial, reducida a su sencillez y contingencia. Por tanto, no se trata ya de que nos muestre la verdad sobre el mundo, ya que por no ser un todo completo su verdad no puede darse de una vez por todas, sino que nos señale la verdad de la vida, de la vida de cada cual.

Esta consideración de que el arte no ocupa el lugar primordial podría llevarnos a pensar que es a la religión a la que le corresponde ese lugar. De ahí que en la segunda parte del libro, Inciarte vuelva a hacernos partícipes de su tensión vital ${ }^{24}$, especialmente mediante el diálogo con Hegel. En esta ocasión la tensión se presenta entre la religión y la filosofía, entre la posibilidad de que todos los contenidos de la fe sean explicados de forma racional y objetiva o, por el contrario, que algunos de ellos supongan un límite misterioso para la razón humana.

\footnotetext{
${ }^{23}$ Es precisamente la importancia que Inciarte da a la vida que no la confunde con ninguna de otra realidad: "Por mucho que el arte se acerque a la vida de la que se alimenta, los dos no pueden nunca llegar a fundirse del todo. Arte es arte y no vida, y lo mismo la filosofía: filosofía, incluido la filosofía de la vida, es filosofía, y no vida” (Inciarte, 2016: 204-205).

${ }^{24}$ Hablo de su tensión vital porque estos capítulos forman de una particular autobiografía, al tiempo personal e intelectual. En ella queda de manifiesto que el autor no se plantea estas cuestiones de manera exclusivamente teórica, sino que muestra una tensión existencial que ha sufrido en sus propias carnes.
} 
Para Hegel, como hemos visto, la filosofía está en el culmen del sistema debido a que es la expresión más racional del sistema y puede dar cuenta de las esferas anteriores, algo que no sucede a la inversa. El planteamiento hegeliano y, en general, el esquema racionalista de la modernidad ha tendido a ensalzar el discurso filosófico por considerarlo el más racional y objetivo y a arrinconar el discurso religioso, teológico, por considerarlo demasiado subjetivo, lo que en este caso se habría vuelto sinónimo de irracional (Inciarte, 2016: 181). Inciarte achaca especialmente a Hegel el hecho de que, al haber otorgado tanto peso a la razón, considera que con ello puede darse explicación de todo. Es decir, no le achaca tanto su racionalismo idealista como su holismo, su intento de dar cuenta de toda la realidad, creyendo que no hay nada más allá de lo explicado.

En contraste con esta interpretación, Inciarte sería más partidario de defender una concepción abierta de razón. Esta apertura de la razón es la que le hace considerar como válidos y racionales los discursos de la religión, siempre que estén sustentados en el desarrollo de un pensamiento teológico racional. La aceptación de racionalidad de los contenidos de la fe, lejos de anular la razón, lo que hace es estimularla al presentarle una realidad que no podría conocer por la mera especulación (Inciarte, 2016: 259). Así, la apertura no sólo tiene que ver con la fe, sino que aparece como una propuesta de apertura a la realidad, que siempre trasciende la razón (Inciarte, 2016: 238).

De nuevo, podríamos considerar que lo que le interesa a este filósofo es mostrar la racionalidad de la religión y así salvar la fe. Pero del mismo modo que en el caso anterior no se ha decantado por ninguno de los dos términos (arte-religión) sino que ha disuelto la tensión en la vida, tampoco ahora con- 


\section{La primacía entre arte, religión y filosofía}

sidera que se trate de elegir entre la filosofía o la religión. Más bien, lo que muestra es que cuando la razón se mira a sí misma, sin apertura a la realidad, a la vida, se queda atrofiada y que una fe que no cuente con la ayuda de la razón se convierte en mero fideísmo. El enfoque excesivamente teórico parece obligar a elegir entre uno de los términos, pero Inciarte señala que si abrimos la razón y alcanzamos la vida podremos ver cómo los diferentes términos se ven imbricados entre sí y la verdad es mucho más rica de lo que podemos alcanzar a comprender. De ahí el interés que tiene a este respecto el trabajo que Inciarte dedicó al estudio no sólo de la verdad teórica sino de la verdad práctica (Inciarte, 1970; 1986; 1994; 1999). Me atrevería a decir que este interés por la verdad práctica muestra su preocupación por cómo poder llevar la vida a plenitud y lo consciente que era de que es en la vida donde todo se pone en juego, donde verdaderamente te la juegas.

\section{Condusión}

A lo largo del texto se han revisado diferentes respuestas a la cuestión sobre cuál es el ámbito que debe alcanzar la primacía para resolver la fractura abierta por la Ilustración entre arte, religión y filosofía. Los autores románticos vieron en el arte, por su doble faceta sensible e intelectual, la esfera unificadora perfecta. Hegel, en cambio, otorgó todo el peso a la reflexión filosófica, por ser la que podía dar cuenta de toda la realidad. Sin embargo, ambas posiciones arrastran el error ilustrado de considerar que las tensiones entre estos ámbitos se resuelven a nivel teórico. Por el contrario, Inciarte, al experimentar la tensión de forma vital, deja de considerar el problema sólo de 
forma teórica y, por tanto, trata de resolverlo analizando las posiciones que ocupan el arte, la religión y la filosofía no en el sistema sino en la vida. La primacía otorgada en este caso a la vida amplía gratamente el problema y nos devuelve la pregunta, ya que es cada uno quien debe resolver la tensión en su propia vida.

\section{Bibliografía empleada}

R. Assunto, La antigüedad como futuro. Estudio sobre la estética del neoclasicismo europeo, Madrid, Visor, 1990.

J. Benjamin, "La obra de arte en la época de su reproductibilidad técnica", en: Obras completas, libro I, vol. 2, Madrid, Abada, 2008, pp. 7-47.

O. Cubo, "Hegel y el fin del arte", en: Hybris, Revista de Filosofía, 2010 (10-1), pp. 6-19.

P. D'Angelo, Simbolo e arte in Hegel, Roma, Laterza, 1989.

P. D’Angelo, F. Duque (eds.), La religión de la pintura. Escritos de filosofía romántica del arte, Madrid, Akal, 1999.

W. Desmond, "Filosofía del arte a la sombra de Hegel", en: Estudios Filosóficos, 2007 (LVI), pp. 31-51.

J. Domínguez Hernández, “¿Religión del arte o comprensión del arte? La crítica de Hegel al Romanticismo", en: Estudios de Filosofía, 2003 (28), pp. 123-142.

R. Gabás, "Estudio introductorio", en: F. Schelling, Sistema del idealismo trascendental; Filosofia del arte; Investigaciones filosóficas sobre la esencia de la libertad humana y los objetos con ella relacionados; Las edades del mundo; Introducción a la filosofía de la revelación, Madrid, Gredos, 2012, pp. VII-XCIX.

G. W. F. Hegel, "Primer programa de un sistema del idealismo alemán”, en: Escritos de juventud, México, Fondo de Cultura Económica, 1984, pp. 219-220.

—, Fenomenología del espíritu, México, Fondo de Cultura Económica, 2004.

—, Lecciones de estética, Barcelona, Península, 1989.

H. Honour, El Romanticismo, Madrid, Alianza, 1984. 


\section{La primacía entre arte, religión y filosofía}

H. Honour y J. Fleming, Historia mundial del arte, Madrid, Akal, 2002.

S. Houlgate, Freedom, Truth and History: An Introduction to Hegel's Philosophy, London, Routledge, 1991.

F. Inciarte, "Moralidad y sociedad en la Filosofía práctica de Aristóteles", en: Atlántida, Revista del pensamiento actual, 1970 (VIII-47), pp. 533-597.

—, "Practical Truth", en: Persona, Verità e Morale, Roma, Città Nuova Editrice, 1986, pp. 201-215.

-, "Discovery and Verification of Practical Truth", en: L. Gormally (ed.), Moral Truth and Moral Tradition. Essays in Honour of Peter Geach and Elisabeth Anscombe, Dublin, Four Courts Press, 1994, pp. 25-52.

—, "Verdad practica en Aristóteles y Duns Scoto", en: Anuario Filosófico, 1999 (XXXII/1), pp. 251-268.

—, Breve teoría de la España moderna, Pamplona, Eunsa, 2001.

—, "Arte, culto y cultura", en: Imágenes, palabras, signos. Sobre arte y filosofía, Pamplona, Eunsa, 2004, pp. 65-88.

-, La imaginación trascendental en la vida, en el arte y en la filosofía, Pamplona, Eunsa, 2012.

-, Cultura y verdad, Pamplona, Eunsa, 2016.

D. Innerarity, Hegel y el romanticismo, Madrid, Tecnos, 1993.

C. Jamme, "La religión-arte", en: F. Duque (ed.), Hegel. La Odisea del Espiritu, Madrid, Pensamiento, 2010, pp. 183-208.

-, "Romanticismo. Historia y concepto", en: El movimiento romántico, Madrid, Akal, 1998, pp. 5-32.

-, Introducción a la filosofía del mito en la época moderna y contemporánea, Barcelona, Paidós, 1999.

M. D. Jiménez Blanco, Una historia del museo en nueve conceptos, Madrid, Cátedra, 2014.

V. López, J. Rivera de Rosales, “Introducción”, en: F. W. J. Schelling, Sistema del idealismo trascendental, 1988, pp. 9-93.

M. Madureira, "El arte antes del fin del arte. Lugar y función del arte en el joven Hegel" en: C. Oliva (ed.), Figuras. Estética y fenomenología en Hegel, México, Universidad Nacional Autónoma de México, 2009, pp. 41-64. 


\section{Raquel Cascales}

S. Marchán Fiz, La disolución del clasicismo y la construcción de lo moderno, Salamanca, Universidad de Salamanca, 2010.

M. A. Martínez, "La revista Athenäum como órgano programático del primer romanticismo alemán”, en: El camino romántico a la objetividad estética. La filosofía del joven F. Schlegel como programa del primer romanticismo alemán, Murcia, Universidad de Murcia, 1992, pp. 7193.

F. Novalis, Los Aprendices de Sais. Cuento simbólico. La cristiandad o Europa, Lima, Pontificia Universidad Católica del Perú, 2004.

J. F. Overbeck, "El triunfo de la religión sobre las artes", en: P. D’Angelo, F. Duque (eds.), La religión de la pintura. Escritos de filosofía romántica del arte, 1999, pp. 164-172.

T. Pinkard, Hegel. Una biografía, Madrid, Acento, 2001.

O. Pöggeler, Hegels Kritik der Romantik, Bonn, Bouvier, 1956.

Ma . I. Ramírez, Arte y belleza en la Estética de Hegel, Sevilla, Universidad de Sevilla, 1988.

J. Rivera de Rosales, “Actualidad de Hegel para la estética contemporánea”, en: M. Herrero (ed.), G.W.F. Hegel: Contemporary Readings: The Presence of Hegel's Philosophy in the Current Philosophical Debates, Hildesheim, Olms, 2011, pp. 96-116.

R. Safranski, Romanticismo. Una odisea del espíritu alemán, Barcelona, Tusquets, 2009.

D. Sánchez Meca, Modernidad y romanticismo, Madrid, Tecnos, 2013.

F. W. J. Schelling, Sistema del idealismo trascendental, Madrid, Anthropos, 1988.

—, Filosofía del arte, Madrid, Tecnos, 1999.

F. Schiller, Cartas para la educación estética del hombre, Barcelona, Antrophos, 1990.

F. Schlegel, “Sobre la exposición del arte alemán en Roma, 1819”, en: en: P. D’Angelo, F. Duque (eds.), La religión de la pintura. Escritos de filosofía romántica del arte, 1999, pp. 136139.

C. Taylor, Hegel, Barcelona, Anthropos, 2010.

\section{Raquel Cascales Tornel rcascales@unav.e}

